\title{
Addressing varenicline adherence through repackaging in a dose administration aid
}

\author{
Aaron D Drovandi \\ Sherryl G Robertson \\ Bunmi S Malau-Aduli \\ Peta Ann Teague \\ Beverley D Glass
}

College of Medicine and Dentistry, James Cook University, Townsville, QLD, Australia
Correspondence: Aaron D Drovandi Building 047, Pharmacy, I James Cook Drive, James Cook University, Townsville 48I4, QLD, Australia

Tel +6I 7478 I 3437

Fax +6I 747258108

Email aaron.drovandi@jcu.edu.au
This article was published in the following Dove Press journal:

Integrated Pharmacy Research and Practice

23 June 2017

Number of times this article has been viewed

Background: Ensuring adherence to prescribed smoking cessation medications, such as Champix $^{\circledR}$ (varenicline), is essential during a quit attempt as non-adherence can significantly reduce the likelihood of achieving prolonged smoking abstinence. The use of dose administration aids may improve adherence, though medication stability on repackaging is not guaranteed, due to a lack of available data from manufacturers supporting this practice.

Objective: To determine the suitability for repackaging varenicline tartrate tablets into a dose administration aid, by assessing its physical and chemical stability after being repackaged and stored at ambient conditions for 6 weeks.

Methods: Varenicline tartrate $(1.0 \mathrm{mg})$ tablets were repackaged into commercially available Webster-pak ${ }^{\circledR}$ blister compartments and stored for 42 days at ambient conditions characteristic of a Zone IVB climate $\left(30 \pm 2{ }^{\circ} \mathrm{C}\right.$ and $75 \pm 5 \%$ relative humidity) according to the World Health Organization (WHO) guidelines on pharmaceutical stability testing. Physical and chemical tests were performed on the repackaged and control tablets, including an assessment of: tablet thickness, hardness, weight uniformity, friability, dissolution, disintegration, and content uniformity after exposure to ambient conditions and light according to International Council on Harmonisation of Technical Requirements of Pharmaceuticals for Human Use guideline Q1B. Results: Weight, friability, and thickness of the tablets complied with compendial standards. A validated high performance liquid chromatography method was used to confirm that after exposure to light, and repackaging at $30^{\circ} \mathrm{C} / 75 \%$ relative humidity, the tablets remained within the required $95 \%-105 \%$ of the stated drug content. However, tablet hardness and disintegration decreased over time, with tablets becoming softer and undergoing more rapid disintegration in water.

Conclusion: Repackaging $1.0 \mathrm{mg}$ varenicline tartrate tablets into a dose administration aid can be undertaken to improve adherence rates and therefore smoking abstinence rates. This can be performed without compromising either the physical or chemical stability of the tablets.

Keywords: stability, compliance, degradation

\section{Introduction}

Medication adherence is an under-addressed area in health care, with approximately $50 \%$ of patients with a chronic illness not taking their prescribed regimens as directed. ${ }^{1,2}$ As advancements in pharmacotherapeutics mean little if patients do not adhere to their prescribed regimen, increasing medication adherence through a combination of patient and physician-based interventions will likely have a significant effect on medical outcomes. ${ }^{3,4}$ Poor medication adherence to smoking cessation aids has been a long-standing problem in combating tobacco use, including for the most effective smoking cessation aid Champix ${ }^{\circledR}$ ([1.0 mg varenicline tartrate] Pfizer, Inc., New York, 
NY, USA), which requires at least 3 months of therapy to effectively support a quit attempt. ${ }^{5}$ Research into varenicline adherence has found a correlation between prolonged smoking abstinence and adherence to the prescribed varenicline regimen. ${ }^{6,7}$

Dose administration aids (DAAs) are one potential avenue to increase medication adherence, as they can simplify complex regimens by repackaging medications into easilyfollowed compartmentalized devices. ${ }^{8,9}$ The elderly, those with mental illnesses, and those on multiple medications may benefit from the increased convenience and reduced error associated with DAA use. However, there are some issues associated with DAAs, primarily that some medications cannot be physically stored together due to surface interactions, and the risk of compromised physical and/or chemical stability. ${ }^{10}$ Exposure to heat, humidity, oxygen, and light can all contribute to physical degradation of the dosage form and/or chemical degradation of the active pharmaceutical ingredient or excipients in the medication. Medication stability guarantees by manufacturers are also invalidated upon removal from the original packaging, meaning an informed decision is required to be made by health professionals prior to committing to repackaging medications into a DAA. ${ }^{8-11}$

Webster-pak ${ }^{\circledR}$ is a commonly utilized DAA device in community pharmacies in Australia, though they are often used without the availability of published data on the stability of individually repackaged medications. Commonly used and repackaged medications such as aspirin, atenolol, furosemide, and sodium valproate have all been reported to demonstrate physical or chemical instability upon repackaging. ${ }^{12-17}$ The objective of this research was thus to determine the physical and chemical stability of varenicline tartrate, when repackaged into a DAA and stored under ambient temperature and humidity conditions in order to recommend its suitability for repackaging in clinical practice.

\section{Methods}

\section{Conditions}

To determine whether commercial varenicline tartrate tablets are suitable for repackaging, tests were performed to identify any issues in relation to physical or chemical stability between the repackaged and control tablets. Varenicline tablets were purchased from a local pharmacy, removed from their original packaging, and repackaged individually into Multi Dose Webster-pak blister compartments. Gloves and plastic packing tweezers were used to handle tablets, and all tablets had a remaining shelf-life of at least 9 months at the time of sampling.
The DAAs were stored at ambient conditions $\left(30 \pm 2{ }^{\circ} \mathrm{C}\right.$ and $75 \pm 5 \%$ relative humidity) for a period of 42 days in a KBF 720 Climate Chamber (Binder GmbH, Tuttlingen, Germany). Control tablets were removed from their original packaging immediately prior to analysis. A duration of 42 days was chosen as the results of this study are required prior to conducting a randomized controlled trial in which participants are to be given varenicline tartrate tablets repackaged in Webster-pak blister compartments. This duration complies with the Pharmaceutical Society of Australia guidelines which recommend a maximum repackaged duration of 8 weeks. ${ }^{18}$

\section{Physical stability testing}

Weight uniformity, physical appearance, thickness, hardness, friability, dissolution and disintegration rates were all evaluated according to the British Pharmacopeia compendial requirements. Weight uniformity was tested by individually weighing 20 tablets on an AND HM-200 analytical balance. Thickness and hardness of ten tablets were measured using a Vankel VK200 instrument, the disintegration of six tablets was assessed using a Varian VK100 disintegration apparatus, and friability testing of 20 tablets was performed using a Vankel Friabilator. ${ }^{19}$

Dissolution was measured for six tablets using a Vankel VK7000 dissolution apparatus with a $100 \mathrm{~mL}$ vessel by placing a $1.0 \mathrm{mg}$ varenicline tartrate tablet in $100 \mathrm{~mL}$ of reverse osmosis water $(\mathrm{pH} 5.2)$ at $37 \pm 0.5^{\circ} \mathrm{C}$. The rotating paddle was set to $100 \mathrm{r} / \mathrm{min}$, and samples withdrawn at 0 and 45 minutes. Samples were assessed for drug content using high performance liquid chromatography (HPLC) (see following section). The dissolution results were analyzed using a twotailed Mann-Whitney $U$ test ( $p=0.05$ ), performed with IBM SPSS Statistics Version 23 (IBM Corp., Armonk, NY, USA).

\section{Chemical stability testing}

Varenicline tartrate content was measured using an HPLC method validated for specificity, linearity, accuracy, and precision as per the International Council on Harmonisation of Technical Requirements of Pharmaceuticals for Human Use (ICH) guideline Q2/R1. ${ }^{20}$ A Nexera-i LC-2040C 3D liquid chromatograph was used to perform content analysis on samples, using a mobile phase composed of $12 \%$ acetonitrile, $88 \%$ water, and $0.1 \%$ formic acid. An XSelect HSS T3 $5 \mu \mathrm{m}$ $(4.6 \mathrm{~mm} \times 250 \mathrm{~mm})$ column was used with a flow rate of $1 \mathrm{~mL} / \mathrm{min}$, heated to $40^{\circ} \mathrm{C}$. The detection wavelength was set at $237 \mathrm{~nm}$, and the injection volume at $10 \mu \mathrm{L}$.

Photostability testing involved placing 20 tablets in a Webster-pak within a Heraeus Suntest CPS+ with a Solar 
ID65 filter and irradiating at 500 watt $/ \mathrm{m}^{2}$ for 10.6 hours, equating to 1.2 million lux hours of exposure to visible light, and $496 \mathrm{WH} / \mathrm{m}^{2}$ of ultraviolet light. This is in accordance with minimum exposure requirements in $\mathrm{ICH}$ guideline Q1B. ${ }^{21} \mathrm{~A}$ control of 20 tablets (wrapped in aluminum foil) was used to determine the effect of temperature. Content analysis was conducted on control samples, covered and exposed photostability samples, and samples from the tablets stored at ambient conditions. Samples were prepared by crushing 20 tablets in a mortar and pestle, weighing out an amount of powder equivalent to one varenicline tartrate tablet, and dissolving in water. Samples were filtered through a Millex-GP $0.22 \mu \mathrm{m}$ polyethersulfone-membrane express filter and analyzed by HPLC using a calibration curve in the range of 0 to $20 \mu \mathrm{g} / \mathrm{L}$.

\section{Results}

\section{Physical stability}

Tablet appearance did not change after storage under ambient conditions, or after exposure to visible and ultraviolet light, with each tablet retaining their blue hue and oblong shape. A minor increase in tablet weight and thickness occurred after storage at ambient temperature and humidity, with the average tablet weight increasing by $1 \%$, and average tablet thickness increasing by $4 \%$. Significant changes in tablet hardness occurred, with the mean pressure to break the control tablets being $151 \mathrm{~N}$, which decreased by $27 \%$ after storage at ambient conditions, to an average of $110 \mathrm{~N}$. These changes led to brief adhesion to the sides of blister cells, though tablets dislodged quickly when moving the DAA, and did not cause any visual residue on the sides of the blister cells.

Disintegration times were also reduced, with control tablets disintegrating in 79 seconds, compared to 66 seconds for the ambient tablets, a reduction of $16 \%$. Figure 1 illustrates the changes in hardness and disintegration times and the relationship between these two physical characteristics. Friability testing resulted in a small amount of weight gain per tablet in both groups, with tablets in the control group gaining an average of $85 \mu \mathrm{g}$, compared to $260 \mu \mathrm{g}$ in the ambient group. Tablet dissolution was unaffected by the repackaging process, with samples taken after 45 minutes averaging $92 \%$ of drug content dissolved for the control tablets, and $93 \%$ for the tablets stored at ambient conditions $(p=0.887)$.

\section{Chemical stability}

Content analysis results of the covered tablets and the tablets exposed to light, and control tablets and those stored at ambient conditions $\left(30^{\circ} \mathrm{C} / 75 \%\right.$ relative humidity) were all within the requirements of the compendial standard. There was no

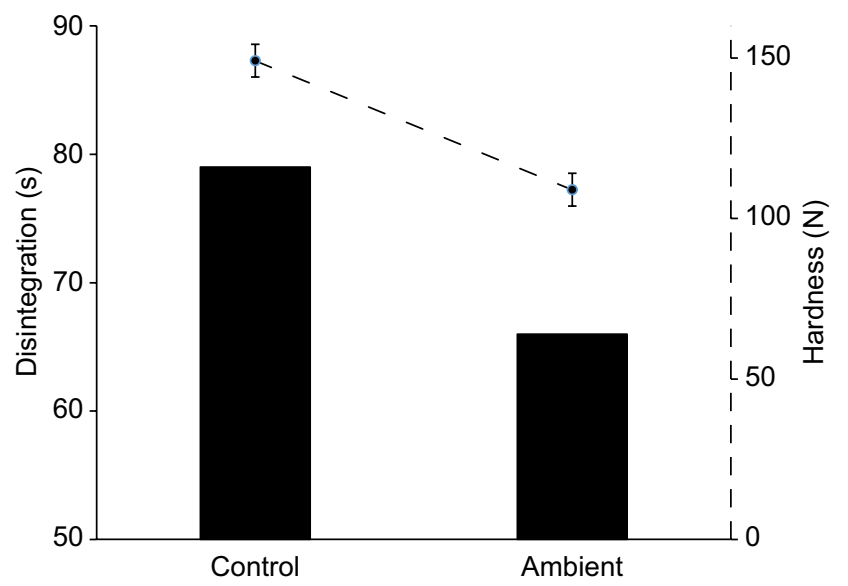

Figure I Variation in $1.0 \mathrm{mg}$ varenicline tartrate tablet disintegration times (bars) and hardness (dotted line) between control tablets, and tablets stored at ambient conditions for 6 weeks.

Note: Error bars represent $95 \%$ confidence intervals about the mean for $n=10$ samples.

Table I Content with $95 \%$ confidence intervals (Cls) for $1.0 \mathrm{mg}$ varenicline tartrate control tablets compared with those exposed to ambient temperature and humidity, and those exposed to light

\begin{tabular}{lllll}
\hline \multicolumn{2}{l}{ Storage conditions } & & \multicolumn{2}{l}{ Photostability conditions } \\
\cline { 1 - 2 } \cline { 5 - 6 } Control \% & Ambient $^{\alpha} \%$ & & Covered \% & Exposed ${ }^{\beta} \%$ \\
\hline 99.3 & 100.5 & & 100.9 & I00.4 \\
(Cl 97.4-101.2) & $($ Cl 96.8-104.2) & & (Cl 95.6-106.2) & (Cl 99.0-10I.8) \\
\hline
\end{tabular}

Notes: ${ }^{\alpha}=30 \pm 2{ }^{\circ} \mathrm{C}$ and $75 \pm 5 \%$ relative humidity for 42 days; ${ }^{\beta}=1.2$ million lux hours visible light and $496 \mathrm{WH} / \mathrm{m}^{2}$ ultraviolet light.

significant difference in varenicline tartrate content between the four groups. Table 1 displays the content averages and $95 \%$ confidence intervals for the samples taken from the tablets within each group.

\section{Discussion}

Ensuring the physical and chemical stability of medications is essential when attempting to reduce patient error and improve medication adherence by repackaging into a DAA such as a Webster-pak. ${ }^{8-12}$ Varenicline tartrate content was not affected by repackaging and storage for 6 weeks at the worst temperature and humidity conditions for long-term stability testing recognized by the WHO. ${ }^{22}$ Though the $0.5 \mathrm{mg}$ varenicline tablets were not tested, it is not believed their results would differ from the $1.0 \mathrm{mg}$ tablets, as the only excipient difference is the coloring agent, and their duration of use in varenicline therapy is only 7 days at the beginning of therapy, minimizing their duration in the DAA.

Tablet hardness and disintegration times, although significantly affected, did not result in compromised physical stability of the dosage form or chemical stability of the drug. Commercially available varenicline tartrate tablets are pack- 
aged in small, individual compartments with an aluminum backing within a cardboard sleeve, allowing significant protection from light, oxygen, and moisture. The Consumer Medicine Information leaflet also recommends storing the tablets in a cool, dry place below $30^{\circ} \mathrm{C}$, specifically mentioning not to store them in the bathroom, near a sink, in the car, or on a window sill, and not to remove tablets from their packaging until a dose is needed. ${ }^{23,24}$

A retrospective study of a cohort of 1,477 patients in a community-based setting found that zero and partial $(<80 \%)$ adherence had similar cessation rates $(31.2 \%$ and $27.8 \%)$ respectively, whereas those who exhibited full adherence attained cessation rates of $50.7 \%{ }^{6}$ A similar result was seen in the COMPASS Smoking Cessation Intervention Trial, with good adherence ( $>80 \%$ ) being associated with a $52 \%$ cessation rate at 6 months, compared to poor adherence, which resulted in a $25 \%$ cessation rate. ${ }^{7}$ Poor adherence (and premature medication discontinuation) is often attributed to adverse effects, as well as smokers either having a perceived lack of efficacy or need for the medication. ${ }^{5,25}$

While Webster-pak blister compartments assist in adherence when using multiple medications through the repackaging of tablets into individual compartments protected by an aluminum backing, the lack of a cardboard sleeve and the presence of a larger internal area for oxygen and moisture result in an increased exposure to light, oxygen, and moisture. An issue not addressed in this study is the potential for surface interactions between multiple medications packaged within the same blister compartment. Whilst individual varenicline tartrate tablets can be safely repackaged into their own Webster-pak blister compartments, further research is required to assess this effect in other forms of DAAs. There is also the need to assess the likelihood of surface interactions and subsequent degradation of either varenicline or other medications in contact with each other.

\section{Conclusion}

The DAA utilized in this study is one of the most commonly used in Australia, with pharmacists often seeking evidencebased recommendations on safe repackaging practices, as manufacturer assurances on stability are invalidated through repackaging. This is needed for both long-term and short-term medications, and those with unusual loading or unloading periods, such as varenicline tartrate. This study shows that $1.0 \mathrm{mg}$ varenicline tartrate tablets repackaged in a Webster-pak will remain stable for a reasonable in-use period of 6 weeks when stored appropriately in tropical climates.

\section{Acknowledgments}

The authors would like to acknowledge Pfizer Inc. for the donation of the pure varenicline tartrate powder for HPLC method development, and Webstercare for their donation of Webster-pak blister compartments to the authors for use in the stability testing. This research received no specific grant from any funding agency, commercial, or not-forprofit sectors.

\section{Disclosure}

The authors report no conflicts of interest in this work.

\section{References}

1. Sabatè E, editor. Adherence to Long-Term Therapies: Evidence for Action. Geneva, Switzerland: World Health Organization; 2003.

2. Vrijens B, De Geest S, Hughes DA, et al. A new taxonomy for describing and defining adherence to medications. Br J Clin Pharmacol. 2012; 73(5):691-705.

3. Haynes RB, Ackloo E, Sahota N, McDonald HP, Yao X. Interventions for enhancing medication adherence. Cochrane Database Syst Rev. 2008;(2):CD000011.

4. Brown MT, Bussell JK. Medication adherence: WHO cares? Mayo Clin Proc. 2011;86(4):304-314.

5. Balmford J, Borland R, Hammond D, Cummings KM. Adherence to and reasons for premature discontinuations from stop-smoking medications: data from the ITC Four-Country Survey. Nicotine Tob Res. 2011;13(2): 94-102.

6. Liberman JN, Lichtenfeld MJ, Galaznik A, et al. Adherence to varenicline and associated smoking cessation in a community-based patient setting. J Manag Care Pharm. 2013;19(2):125-131.

7. Catz SL, Jack LM, McClure JB, et al. Adherence to varenicline in the COMPASS smoking cessation intervention trial. Nicotine Tob Res. 2011;13(5):361-368.

8. Haywood A, Glass BD. Evidence of stability of medicines repackaged in compliance aids: a review. Curr Drug Saf. 2016;11(1):69-77.

9. Roberts M, Stokes J, Ientile C, Lewis G, Doran C, Haywood A, et al. Effectiveness and cost effectiveness of dose administration aids (DAAs): Phase 3 Final report. Quality Medication Care Pty Ltd \& Therapeutic Research Unit, School of Medicine, University of Queensland, 2006. Available from http://6cpa.com.au/wp-content/uploads/Effectivenessand-cost-effectiveness-of-Dose-Administration-Aids-phase-3-DAAphase-3-Final-Report.pdf . Accessed December 15, 2016.

10. Glass BD, Haywood A, Llewelyn V, Mangan M. Compliance aids and medicine stability: new evidence of quality assurance. Curr Drug Saf. 2009;4(1):74-78.

11. Church C, Smith J. How stable are medicines moved from original packs into compliance aids? Pharm J. 2006;276(7384):75-81.

12. Mylrea M, Robertson S, Haywood A, Glass B, Fersterer C. Clinical pharmacy: Dispersible aspirin tablets repackaged into dosette boxes: Caution in Practice. Australas J Pharm. 2013;94(1113):60-63.

13. Chan K, Swinden J, Donyai P. Pilot study of the short-term physiochemical stability of atenolol tablets stored in a multi-compartment compliance aid. Eur J Hosp Pharm Sci Pract. 2007;13(3):60-66.

14. Donyai P. Quality of medicines stored together in multi-compartment compliance aids. J Clin Pharm Ther. 2010;35(5):533-543.

15. Bowen L, Mangan M, Haywood A, Glass BD. Stability of frusemide tablets repackaged in dose administration aids. Journal of Pharmacy Practice and Research. 2007;37(3):178-181.

16. Llewelyn VK, Mangan MF, Glass BD. Stability of sodium valproate tablets repackaged in dose administration aids. J Pharm Pharmacol. 2010;62(7):838-843. 
17. Redmayne B, Robertson S, Kockler J, Llewelyn V, Haywood A, Glass B. Repackaged sodium valproate tablets--meeting quality and adherence to ensure seizure control. Seizure. 2015;31:108-111.

18. Pharmaceutical Society of Australia [homepage on the Internet]. Dose Administration Aids Service: Guidelines and standards for pharmacists. Pharmaceutical Society of Australia, 2007. Available from: http:// www.psa.org.au/practice-standards/dose-administration-aids-service. Accessed May 23, 2017.

19. British Pharmacopoeia. Appendix XII. London: British Pharmacopoeia Commission; 2014.

20. ICH Harmonised Tripartite Guideline. Validation of Analytical Procedures: Text and Methodology Q2(R1). Geneva: ICH Steering Committee; 2005. Available from: https://www.ich.org/fileadmin/ Public_Web_Site/ICH_Products/Guidelines/Quality/Q2_R1/Step4/ Q2_R1_Guideline.pdf. Accessed May 23, 2017.
21. ICH Harmonised Tripartite Guideline. Stability Testing: Photostability testing of new drug substances and products Q1B. Geneva: ICH Steering Committee; 1996. Available from: https://www.ich.org/fileadmin/ Public_Web_Site/ICH_Products/Guidelines/Quality/Q1B/Step4/ Q1B_Guideline.pdf. Accessed May 23, 2017.

22. World Health Organization. Stability Testing of active pharmaceutical ingredients and finished pharmaceutical products. World Health Organization Technical Report Series; 2009:953:87-130.

23. Monthly Index of Medical Specialties. (2015). MIMS Full Prescribing Information: Champix. Revised July 1, 2015. Retrieved October 15, 2016.

24. Monthly Index of Medical Specialties. (2015). Consumer Medicine Information: Champix. Revised October 2015. Retrieved October 15, 2016.

25. Drovandi AD, Chen CC, Glass BD. Adverse effects cause varenicline discontinuation: a meta-analysis. Curr Drug Saf. 2016;11(1):78-85.
Integrated Pharmacy Research and Practice

\section{Publish your work in this journal}

Integrated Pharmacy Research and Practice is an international, peer-reviewed, open access, online journal, publishing original research, reports, reviews and commentaries on all areas of academic and professional pharmacy practice This journal aims to represent the academic output of pharmacists and pharmacy practice with particular focus on integrated care. All papers are carefully

\section{Dovepress}

peer reviewed to ensure the highest standards as well as ensuring that we are informing and stimulating pharmaceutical professionals. The manuscript management system is completely online and includes a very quick and fair peer-review system, which is all easy to use. Visit http://www.dovepress.com/ testimonials.php to read real quotes from published authors.

Submit your manuscript here: http://www.dovepress.com/integrated-pharmacy-research-and-practice-journal 